\title{
A graph-based approach and an interactive tool for preliminary digital prototyping
}

\author{
Ferdinando Vitolo ${ }^{1}\left[\right.$ : Stanislao Patalano ${ }^{1} \cdot$ Antonio Lanzotti $^{1}$
}

Received: 12 March 2020 / Accepted: 7 October 2020 / Published online: 23 October 2020

(C) The Author(s) 2020

\begin{abstract}
Design process is usually based on past experiences and best practises which compose the company know-how. The challenge is to identify common patterns in the design solutions generated for different design problems. The present paper focuses on the identification of product patterns by using a graph-based approach. It deals with the designing of automotive gearboxes and with the development of an approach and a software tool aimed to support preliminary design and CAD modelling activities in gearbox designing. The approach is applied to two different architectures of manual transverse gearboxes characterized by two and three shafts. It aims at the identification of common design features through the detection of the directed graphs matching. A Matlab software tool for gearbox preliminary design is implemented according to the detected common features. The proposed approach and the developed software tool provide an effective way to keep and re-use company know-how, especially in the context of large automotive companies.
\end{abstract}

Keywords $\mathrm{KBE} \cdot$ Product pattern $\cdot$ Graph theory $\cdot \mathrm{CAD}$ modelling $\cdot$ Graphical user interfaces

\section{Introduction}

Design process is often based on company best practises and know-how. Some specific design contexts are deeply specialised and make use of dedicated approaches [3]. In many other cases, the common design phase is strictly based on company knowledge and it doesn't start from scratch.

Knowledge managing techniques and approaches, in terms of data acquisition, organisation and re-use, take on a key role. By tackling a new problem, the main objective is the re-use of past experiences, as well as past solutions, for adopting or adapting to the new problem [9].

The identification and organization of product pattern enable an easier re-using process.

Ferdinando Vitolo

ferdinando.vitolo@unina.it

Stanislao Patalano

stanislao.patalano@unina.it

Antonio Lanzotti

antonio.lanzotti@unina.it

1 Fraunhofer JL IDEAS - Department of Industrial Engineering, University of Naples Federico II, P.le Tecchio, 80, 80125 Naples, Italy
The present paper focuses on the identification of product patterns by using a graph-based approach [5-7] in order to support the design activity. In particular, the use of directed graphs [2] as data manager improves the management and re-use of company know-how, according to a KBE point of view, and allows the creation of an easy-to use Graphical User Interface (GUI). The GUI is the software tool that allows designer to identify relations between design features, to manage and distribute engineering knowledge and to improve standardization within design processes.

The approach is applied to two gearboxes characterized, respectively, by a two-shafts and three-shafts architecture, with a particular focus on the identification of common design features belonging to different gearbox architectures, in order to accomplish the geometric modelling of mechanical assembly and support the preliminary phase of dimensioning as well as the updating of CAD models during re-design activities.

\section{Graph-based approach}

The approach uses a detail multi-level definition defined in [5-7]. It combines the principles of the Axiomatic Design [8] and directed graph (digraph) to clearly represents the 
dependencies between the parameters for any level of the product hierarchical structure [2]. Therefore, once the level of detail is defined, it is possible to associate a digraph for the "transversal" dependencies within the level.

The approach consists of two parts [6]; the first one for the construction of the digraph (done only once); the second one for re-use of information in design phase.

When dealing with a complex product, the first step is the brake-down decomposition up to detail level of part [1]. To define the dependencies among the parts is necessary to make a digraph for the level obtained, level of part in this case. The digraph could be exploded up to the features/parameters level with the specification of new relations which define intopart dependencies. In order to carry out features/parameters, digraph need to deeply know the assembly or have a lot of information on it. Generally, three digraphs are needed for the full representation of an assembly:

1. Assembly digraph, that represents the dependencies among the parts of the assembly;

2. Layout digraph, that represents the dependencies among the geometric features;

3. Feature digraph, that represents the dependencies among the features/parameters of the parts and, then, the assembly.

Digraph can be applied for the re-use of information disengaged from geometry in development software tools activity and product design activity, respectively. It allows to record and manage company knowledge in the product development processes. You fail to make a more efficient redesign of the product/assembly. With a software interface becomes much easier and faster retrace, every time, the design cycle tracing the digraph.

\section{Case study}

The proposed approach is applied to two different architectures of manual transverse gearboxes characterized, respectively, by two and three transmission shafts (Fig. 1). The digraphs obtained (Fig. 2) are used to detect the gearbox patterns and figure out the common aspects, features and parameters that can be re-used.

Based on the identified patterns, a software tool for preliminary design of gearboxes (previously developed [4]) has been implemented.

\section{Conclusions}

The paper presents an approach, based on the graph theory, to face the management and re-using of company know-how,

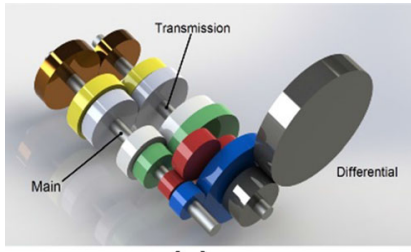

(a)

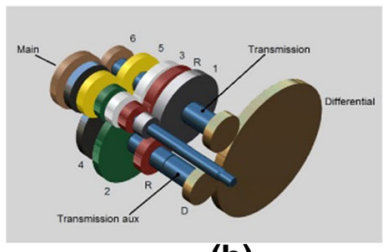

(b)
Fig. 1 Simplified model of gearboxes (pitch diameters): a) two transmission shafts; b) three transmission shafts

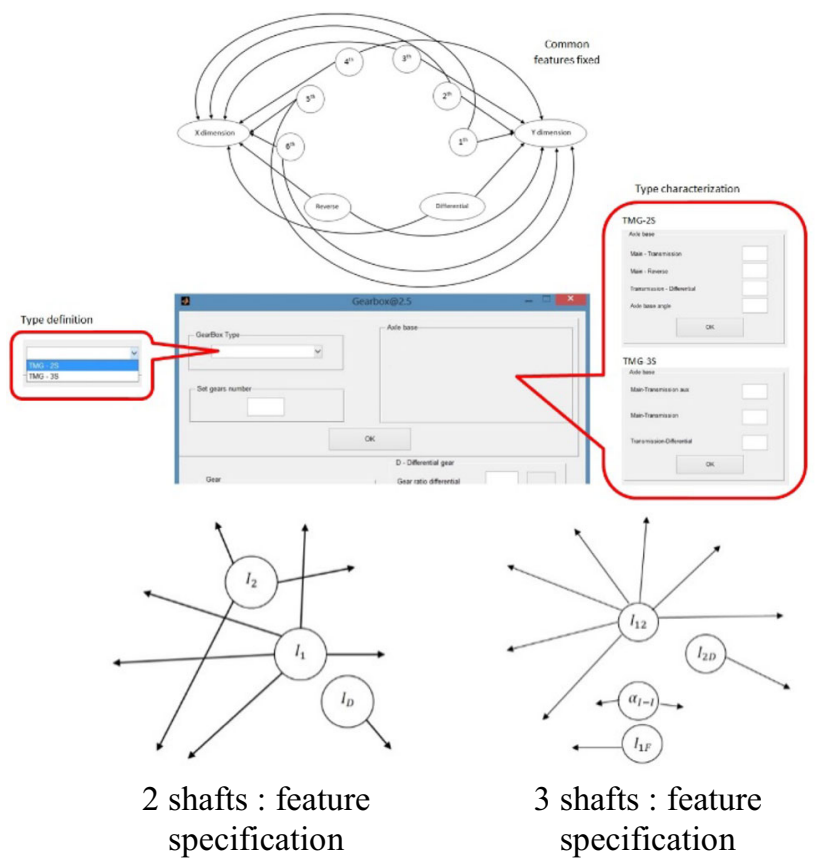

Fig. 2 GUI layout based on re-use of common features

according to a KBE methodology. The paper deals with a designing approach deepening two different architectures of manual transverse gearboxes. The approach detects the common features existing between different gearboxes, through a graph representation. These data are the starter point to perform the re-use of company knowledge. After identified gearbox common features, the set of parameters and dimensioning rules are defined. Therefore, an interactive software tool for the sizing and the preliminary CAD modelling of the examined gearboxes was accomplished.

Funding Open access funding provided by Università degli Studi di Napoli Federico II within the CRUI-CARE Agreement..

Open Access This article is licensed under a Creative Commons Attribution 4.0 International License, which permits use, sharing, adaptation, distribution and reproduction in any medium or format, as long as you give appropriate credit to the original author(s) and the source, provide a link to the Creative Commons licence, and indicate if changes were made. The images or other third party material in this article are included in the article's Creative Commons licence, unless indicated otherwise in a credit line to the material. If material 
is not included in the article's Creative Commons licence and your intended use is not permitted by statutory regulation or exceeds the permitted use, you will need to obtain permission directly from the copyright holder. To view a copy of this licence, visit http://creativecomm ons.org/licenses/by/4.0/.

\section{References}

1. Chen, X., Gao, S., Yang, Y., Zhang, S.: Multi-level assembly model for top-down design of mechanical products. Comput. Aided Des. 44, 1033-1048 (2012)

2. Deo, N.: Graph theory with applications to engineering and computer science, PHI Learning 2004, New Delphi (2004)

3. Labate, C., Di Gironimo, G., Renno, F.: Plasma facing components: a conceptual design strategy for the first wall in FAST tokamak. Nucl. Fusion 55, 113013 (2015). https://doi.org/10.1088/0029-551 5/55/11/113013

4. Patalano, S., Lanzotti, A., Del Giudice, D.M., Vitolo, F., Gerbino, S.: On the usability assessment of the graphical user interface related to a digital pattern software tool. Int. J. Interact. Des. Manuf. 11(3), 457-469 (2017)

5. Patalano, S., Vitolo, F., Lanzotti, A.: A Graph-based Software Tool for the CAD Modeling of Mechanical Assemblies. In GRAPP/IVAPP, pp. 60-69 (2013)
6. Patalano, S., Vitolo, F., Lanzotti, A.: A digital pattern approach to 3D CAD modelling of automotive car door assembly by using directed graphs. In: Zawiślak, S., Rysiński, J. (eds.) Chapter in Graph-Based Modelling in Engineering, Mechanisms and Machine Science Series, vol. 42, 175-185. Springer, Berlin. ISBN 978-3-31939018-5 (2016)

7. Patalano, S., Vitolo, F., Lanzotti, A.: A Digital Pattern Approach to 3D CAD Modelling of Automotive Car Door Assembly by Using Directed. Graphs Graph-Based Modelling in Engineering, pp. 175-185. Springer, Cham (2017)

8. Suh, N.P.: The Principles of Design. Oxford University Press, New York (1990)

9. Tang, D., Zhu, R., Tang, J., Xu, R., He, R.: Product Design Knowledge Management Based on Design Structure Matrix. Adv. Eng. Inform. 24, 159-166 (2010)

Publisher's Note Springer Nature remains neutral with regard to jurisdictional claims in published maps and institutional affiliations. 